\title{
Proteome analysis reveals roles of L-DOPA in response to oxidative stress in neurons
}

\author{
Mohammad-Saeid Jami ${ }^{1,4}$, Ramavati Pal ${ }^{1}$, Esthelle Hoedt ${ }^{2}$, Thomas A Neubert ${ }^{2}$, Jan Petter Larsen ${ }^{3}$ \\ and Simon Geir Møller ${ }^{1,3^{*}}$
}

\begin{abstract}
Background: Parkinson's disease (PD) is the second most common neurodegenerative movement disorder, caused by preferential dopaminergic neuronal cell death in the substantia nigra, a process also influenced by oxidative stress. L-3,4-dihydroxyphenylalanine (L-DOPA) represents the main treatment route for motor symptoms associated with PD however, its exact mode of action remains unclear. A spectrum of conflicting data suggests that L-DOPA may damage dopaminergic neurons due to oxidative stress whilst other data suggest that L-DOPA itself may induce low levels of oxidative stress, which in turn stimulates endogenous antioxidant mechanisms and neuroprotection.

Results: In this study we performed a two-dimensional gel electrophoresis (2DE)-based proteomic study to gain further insight into the mechanism by which L-DOPA can influence the toxic effects of $\mathrm{H}_{2} \mathrm{O}_{2}$ in neuronal cells. We observed that oxidative stress affects metabolic pathways as well as cytoskeletal integrity and that neuronal cells respond to oxidative conditions by enhancing numerous survival pathways. Our study underlines the complex nature of L-DOPA in PD and sheds light on the interplay between oxidative stress and L-DOPA.
\end{abstract}

Conclusions: Oxidative stress changes neuronal metabolic routes and affects cytoskeletal integrity. Further, L-DOPA appears to reverse some $\mathrm{H}_{2} \mathrm{O}_{2}$-mediated effects evident at both the proteome and cellular level.

Keywords: Parkinson's disease, Oxidative stress, Dopamine, Proteomics

\section{Background}

Parkinson's disease (PD) is the second most common neurodegenerative movement disorder, affecting approximately $1 \%$ of individuals older than 60 years [1]. The occurrence of PD will most likely double within the next two decades due to an increase in the aging population [2]. PD is caused by preferential dopaminergic neuronal cell death in the substantia nigra, resulting in a reduced level of dopamine in the striatum. By the time of clinical diagnosis this region of the brain has irreversibly lost 50 $70 \%$ of its neurons compared to unaffected individuals [3]. Despite PD being a complex and multifactorial disease, oxidative stress and mitochondrial dysfunction are thought to be major causes of neurodegeneration in PD [4]. In both idiopathic and genetic PD, oxidative stress is thought to be a common denominator and the substantia

\footnotetext{
* Correspondence: mollers@stjohns.edu

'Department of Biological Sciences, St John's University, New York, NY, USA

${ }^{3}$ The Norwegian Centre for Movement Disorders, Stavanger University

Hospital, Stavanger, Norway

Full list of author information is available at the end of the article
}

nigra of PD subjects exhibit increased levels of oxidized lipids [5], proteins and DNA [6] and decreased levels of reduced glutathione (GSH) [7].

L-3,4-dihydroxyphenylalanine (L-DOPA) remains the most common PD medication as it is converted into dopamine in dopaminergic neurons temporarily relieving motor symptoms. Despite its widespread use there is clear controversy in the field. Pre-clinical in vivo studies have shown that L-DOPA can damage dopaminergic neurons due to oxidative stress and perhaps through other mechanisms $[8,9]$. Studies have shown that direct intraniagral infusion of L-DOPA in rats results in reduced dopaminergic neuron numbers [10] whilst other studies have demonstrated that L-DOPA increases the levels of nitric oxide in the substantia nigra and striatum $[11,12]$. In contrast, many in vitro studies have shown that L-DOPA may be neuroprotective through decreased lipid peroxidation [13,14]. Furthermore, studies have indicated that L-DOPA can act as a neuroprotective agent reducing toxicity evoked by stronger oxidants [15]. Indeed, whether L-DOPA is neurotoxic, or has little to 
no effect on dopaminergic neuron survival, still remains unanswered [16].

Despite numerous studies, the molecular interplay between oxidative stress and L-DOPA remains fragmented. In this study we have performed a two-dimensional gel electrophoresis (2DE)-based proteomic study to gain further insight into the effects of L-DOPA in response to $\mathrm{H}_{2} \mathrm{O}_{2}$-mediated oxidative stress in SH-SY5Y neuronal cells. We show that L-DOPA influences proteome changes in response to oxidative stress leading to a lowering of reactive oxygen species (ROS) and increased cell survival indicative of a role in neuronal cell protection.

\section{Results and discussion}

\section{Cell morphology, viability and proteomic profiling of} neuronal cells in response to $\mathrm{H}_{2} \mathrm{O}_{2}$ and L-DOPA treatment In order to provide a global overview regarding the mechanism in which L-DOPA may influence toxic effects of $\mathrm{H}_{2} \mathrm{O}_{2}$ in neuronal cells we performed cell viability analysis and subsequent proteomic analyses using SH-SY5Y cells. Although primary neurons or dopaminergic neurons would be ideal for this study in relation to PD we selected SH-SY5Y cells based on reproducibility and because they are dopamine beta hydroxylase active. SH-SY5Y cells were grown under control conditions and were exposed to $2 \mathrm{mM} \mathrm{H}_{2} \mathrm{O}_{2}, 200 \mu \mathrm{M}$ L-DOPA or a combination of the two treatments ( $2 \mathrm{mM} \mathrm{H}_{2} \mathrm{O}_{2} / 200 \mu \mathrm{M}$ L-DOPA) for eight hours. Cell morphology analysis (Figure 1A) and cell viability assays (Figure 1B) demonstrated that SH-SY5Y cells exposed to L-DOPA showed no effect on morphology or cell viability (Figure 1). By contrast, $\mathrm{H}_{2} \mathrm{O}_{2}$ exposure decreased cell viability, but this effect was reversed in response to co-treatment with L-DOPA (Figure 1). This suggested that L-DOPA might have a protective effect towards excess oxidative stress.

Based on these findings we then performed a set of proteomic analyses on SH-SY5Y cells exposed to the same treatments as described above. The first experiment focused on the effects of $\mathrm{H}_{2} \mathrm{O}_{2}$ on the neuronal proteome where we compared the proteome profile of SH-SY5Y cells under control condition (Table 1; Condition A, Figure 2A) to cells treated with $\mathrm{H}_{2} \mathrm{O}_{2}$ (Table 1; Condition $\mathrm{B}$, Figure $2 \mathrm{~B}$ ). In this experiment we observed significant up-regulation of ten proteins (spots 1-10) and significant down-regulation of six proteins (spots 11-16) compared to control condition (Table 1). In a second experiment we compared the proteome profile of cells exposed to LDOPA (Table 1; Condition C, Figure 3A) to control cells and found one detectable protein (spot 17) that changes in response to L-DOPA exposure (Table 2). Finally, in a third experiment we compared the proteome profile from cells exposed to both $\mathrm{H}_{2} \mathrm{O}_{2}$ and L-DOPA (Figure 3B; Condition D) to control cells (Figure 2A; Condition A) and observed up-regulation of five proteins (spots 7-10) and down-regulation of four proteins (spot 14-16 and 18). Interestingly in this comparison spot 17 was detected in response to co-treatment with both $\mathrm{H}_{2} \mathrm{O}_{2}$ and L-DOPA but not in the control (Figures 2 and 3). Although LDOPA can auto-oxidize we did not include catalase in these experiments as our findings show that L-DOPA treatment can reverse the decreased cell viability in response to oxidative stress suggesting the presence of the active form of L-DOPA in our experimental conditions. Detailed information on the number of spots detected in each gel is summarized in Table 1.

We studied and classified the differentially expressed proteins according to their gene ontology (GO, with
A
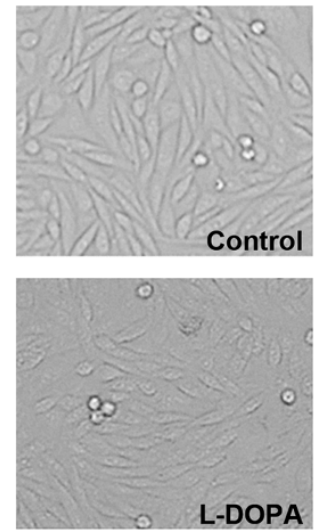

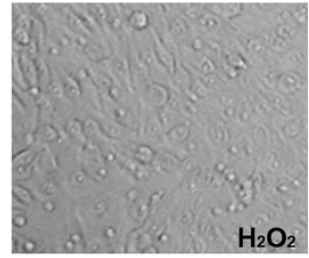

$\mathrm{H}_{2} \mathrm{O}_{2}$

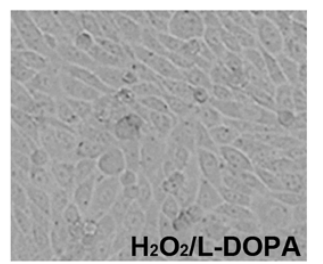

B

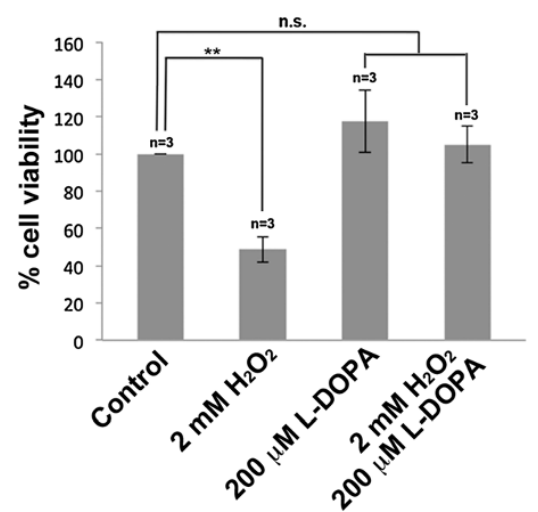

Figure 1 Cell morphology and cell viability of SH-SY5Y cells in response to $\mathrm{H}_{2} \mathrm{O}_{2}$, L-DOPA and $\mathrm{H}_{2} \mathrm{O}_{2} / \mathrm{L}-\mathrm{DOPA}$ treatments. (A) Cell morphology of SH-SY5Y cells in response to eight hours of $2 \mathrm{mM} \mathrm{H}_{2} \mathrm{O}_{2}, 200 \mu \mathrm{M}$ L-DOPA and $2 \mathrm{mM} \mathrm{H}_{2} \mathrm{O}_{2} / 200 \mu M$ L-DOPA treatments. (B) Neutral red cell viability assays of SH-SY5Y cells in response to eight hours of $2 \mathrm{mM} \mathrm{H}_{2} \mathrm{O}_{2}, 200 \mu \mathrm{M} \mathrm{L-DOPA}$ and $2 \mathrm{mM} \mathrm{H}_{2} \mathrm{O}_{2} / 200 \mu \mathrm{M}$ L-DOPA treatments. Each data point is the average of three replicate samples and presented as means $\pm \mathrm{SD}$. Standard deviations are indicated by error bars. ${ }^{* *} p<0.01$. 
Table 1 Treatment conditions of the SH-SY5Y neuronal cells

\begin{tabular}{clrrrr}
\hline Condition & Treatment regime & $\begin{array}{c}\text { Number of spots detected } \\
\text { in three gels }\end{array}$ & $\begin{array}{c}\text { Spots matched } \\
\text { to replicates }\end{array}$ & $\begin{array}{c}\text { Spots matched } \\
\text { to control }\end{array}$ & $\begin{array}{c}\text { Figure } \\
\text { no. }\end{array}$ \\
\hline A & Control & $1252,1326,1277$ & 1212 & - \\
B & $2 \mathrm{mM} \mathrm{H} \mathrm{O}_{2}-8$ hours & $1287,1202,1219$ & 1184 & 1033 \\
C & $200 \mu \mathrm{M} \mathrm{L-DOPA}-8$ hours & $1314,1280,1334$ & 1257 & 1191 \\
D & Co-treatment with $200 \mu \mathrm{M} \mathrm{L-DOPA}$ and $2 \mathrm{mM} \mathrm{H}_{2} \mathrm{O}_{2}-8$ hours & $1285,1274,1239$ & 1215 & 1082 \\
\hline
\end{tabular}

focus on biological process) through Uniprot (protein knowledge website: http://www.uniprot.org/) and QuickGO (http://www.ebi.ac.uk/QuickGO/). Several biological processes and pathways were affected due to the treatment conditions. For instance the majority of protein changes in response to oxidative stress belong to the "cell motion (GO:0006928)" category, most of which were reversed by L-DOPA co-treatment. More detailed information regarding the differentially expressed proteins are illustrated in Figure 4, summarized in Table 2 and discussed below.

\section{Oxidative stress changes metabolic routes}

Glutathione is one of the main cellular antioxidants which prevents damage caused by ROS [17]. The reduced form of glutathione is oxidized during the conversion of reactive $\mathrm{H}_{2} \mathrm{O}_{2}$ into $\mathrm{H}_{2} \mathrm{O}$ by glutathione peroxidase and the oxidized form can be reduced back to its original state via NADPH and glutathione reductase. The main source of $\mathrm{NADPH}$ in cells is through the pentose phosphate pathway (PPP, also called the phosphogluconate pathway).
We observed a dramatic decrease in the expression of glyceraldehyde 3-phosphate dehydrogenase (GAPDH) in all conditions treated with $\mathrm{H}_{2} \mathrm{O}_{2}$ (spot 14 with an average of 0.22 fold change compared to the control) (Table 2). GAPDH catalyzes the conversion of glyceraldehyde 3-phosphate to D-glycerate 1,3-bisphosphate as part of glycolysis. GAPDH also acts as reversible metabolic switch under oxidative stress conditions where cells require excessive amounts of the antioxidant cofactor NADPH [18]. Indeed, it has been shown that oxidative stress causes an inactivation of GAPDH which reroutes the metabolic flux from glycolysis to the PPP [19]. This phenomenon in turn allows cells to produce higher levels of NADPH to overcome the oxidative conditions. Combined with our findings showing $\mathrm{H}_{2} \mathrm{O}_{2}$-mediated down-regulation of GAPDH, GAPDH modulation may have neuroprotective potential [20].

Unlike GAPDH, lactate dehydrogenase (LDH, spot 7, 4.52 fold change) is up-regulated in response to $\mathrm{H}_{2} \mathrm{O}_{2}$ exposure (Table 2). This cytosolic enzyme, involved in oxidation-reduction, can catalyze the conversion of
A

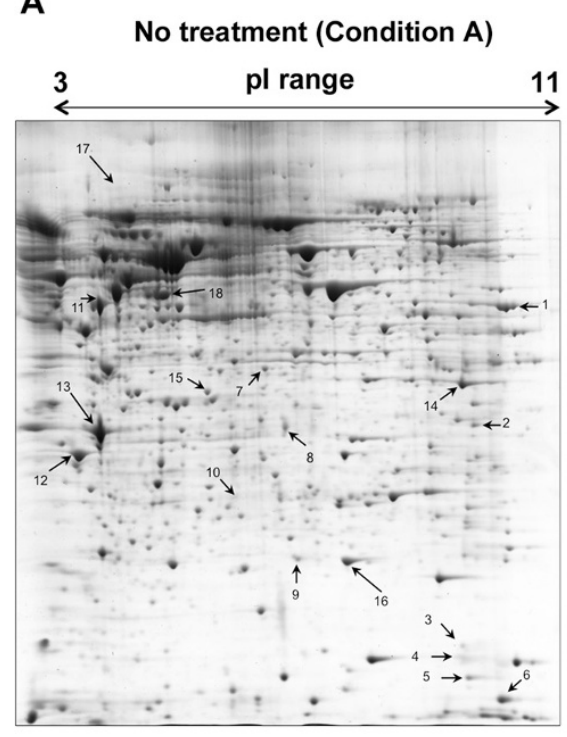

B Treatment with $\mathrm{H}_{2} \mathrm{O}_{2}$ (Condition B)

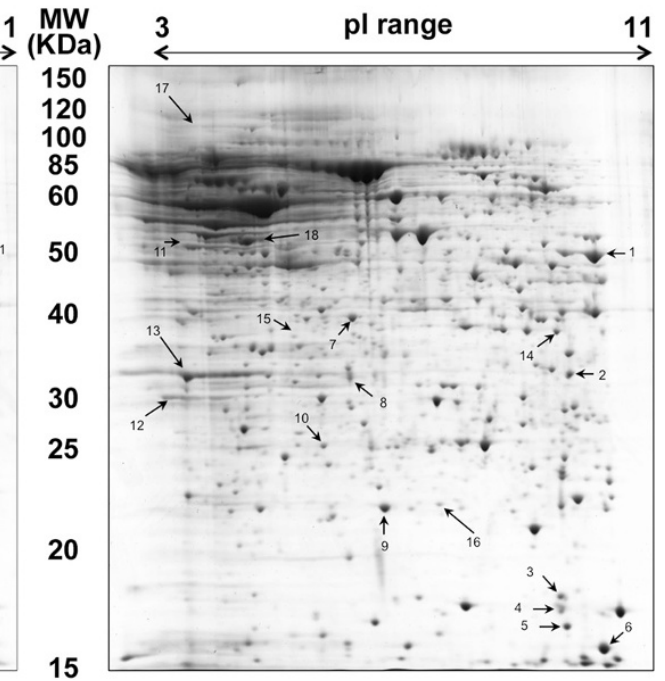

Figure 2 Comparison of the proteomes of SH-SY5Y cells with or without $\mathrm{H}_{2} \mathrm{O}_{2}$. Representative 2-DE gels $(n=3$ for each treatment) of the proteomes of SH-SY5Y cells grown for 8 hours in the (A) absence or (B) presence of $2 \mathrm{mM} \mathrm{H}_{2} \mathrm{O}_{2}$. The uppercase letters are used for those spots overrepresented in each condition whereas lowercase letters are used for spots underrepresented. The spots differentially represented are numbered and correspond to the proteins listed in Table 2. 
A

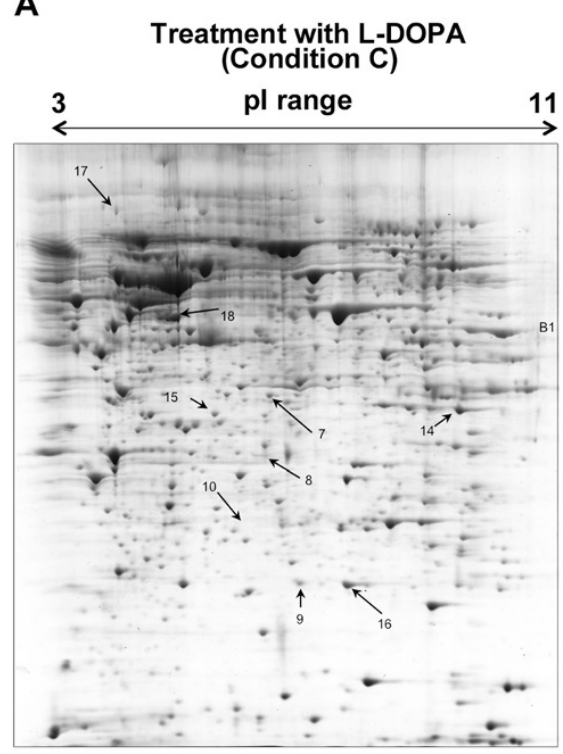

B

Treatment with $\mathrm{H}_{2} \mathrm{O}_{2} / \mathrm{L}-\mathrm{DOPA}$ (Condition D)

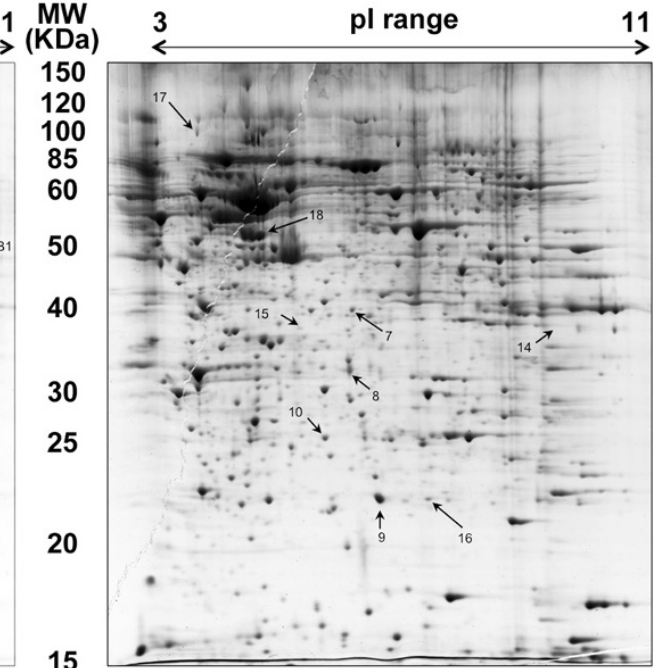

Figure 3 Proteomes of SH-SY5Y cells exposed to L-DOPA with or without $\mathrm{H}_{2} \mathrm{O}_{2}$. Representative 2-DE gels ( $n=3$ for each treatment) of the proteomes of SHSY5Y cells grown in media containing $200 \mu \mathrm{M} \mathrm{L-DOPA}$ for 8 hours in the (A) absence or (B) presence of $2 \mathrm{mM} \mathrm{H}_{2} \mathrm{O}_{2}$. The uppercase letters are used for those spots overrepresented in each condition whereas lowercase letters are used for spots underrepresented. The spots differentially represented are numbered and correspond to the proteins listed in Table 2.

pyruvate to lactate in the absence of oxygen [21]. However, LDH can also perform the reverse reaction in oxidative conditions and generate NADH.

Similar to the cytosolic routes, oxidative stress impacts the tricarboxylic acid (TCA) cycle as well as betaoxidation of fatty acids in mitochondria. We detected substantial up-regulation of fumarate hydratase (spot 1 , 8.27 fold increase) in response to $\mathrm{H}_{2} \mathrm{O}_{2}$, a member of the TCA cycle that catalyzes the reversible hydration/dehydration of fumarate to malate (Table 2). The TCA cycle generates $\mathrm{NADH}$, which can either be used in respiration or be converted to NADPH via nicotinamide nucleotide transhydrogenase (NNT). Interestingly, the alteration of mitochondrial nucleoside-diphosphate kinase (spot 6, 2.7 fold increase), that catalyzes the exchange of phosphate groups between different nucleoside diphosphates, also supports the involvement of the TCA cycle in the oxidative stress response in neurons (Table 2).

Our analysis also showed up-regulation of 3-Hydroxyacyl CoA dehydrogenase (spot 2, 4.81 fold change), an oxidoreductase enzyme involved in beta-oxidation of fatty acids catalyzing oxidation of L-3-hydroxyacyl CoA by NAD + thus generating $\mathrm{NADH}$ in response to oxidative stress (Table 2).

\section{Neurons respond to oxidative conditions by enhancing cell survival mechanisms}

In the oxidative stress conditions tested we observed upregulation of proteins involved in cell survival such as Annexin A1, Peroxiredoxin-6 and PARK7/DJ-1 (Table 2).
Annexin A1 (spot 8, 1.88 fold) is known to be a calcium/phospholipid-binding protein that promotes membrane fusion [22]. This membrane-associated protein can regulate proliferation and apoptosis via the NF- $\mathrm{kB}$ signal transduction pathway [23,24]. Annexin A1 can also directly improve cell survival by limiting excessive levels of ROS during oxidative stress in plant cells. It has been demonstrated that Annexin A1 from Arabidopsis thaliana (AnnAt1) is a redox sensor and displays peroxidase activity [25]. Moreover Rhee and co-workers have shown that, Annexin I serves as a stress protein in HeLa cells and that Annexins may constitute a new class of stress proteins [26].

Similarly, Peroxiredoxin-6, involved in redox regulation of the cell, is highly up-regulated (spot 10, 12.7 fold) in response to $\mathrm{H}_{2} \mathrm{O}_{2}$ exposure (Table 2). Peroxiredoxins represent antioxidants with the capacity to mediate signal transduction in mammalian cells [27]. Indeed, peroxiredoxin- 6 can reduce $\mathrm{H}_{2} \mathrm{O}_{2}$ and short chain fatty acid, and phospholipid hydroperoxides [28]. Moreover, it has been reported that retinal ganglion cells overexpressing Peroxiredoxin-6 gain resistance against hypoxia-evoked generation of ROS and ROS-induced cellular insults by negatively regulating NF- $\mathrm{kB}$-mediated death signaling [29].

The substantial up-regulation of PARK7/DJ-1 (spot 9, 8.58 fold), involved in protecting cells against oxidative stress and cell death, is not entirely surprising (Table 2). PARK7/DJ-1 has numerous reported functions, including anti-oxidative stress reactions, transcriptional regulation, 
Table 2 Detailed information of spots up-regulated or down-regulated in each treatment condition

\begin{tabular}{|c|c|c|c|c|c|c|c|c|c|c|}
\hline $\begin{array}{l}\text { Spot } \\
\text { ID }\end{array}$ & $\begin{array}{l}\text { Protein } \\
\text { ID }\end{array}$ & Description & Mass & PI & Score & $\begin{array}{l}\text { Protein } \\
\text { coverage }\end{array}$ & $\begin{array}{l}\text { AVG fold } \\
\text { change }\end{array}$ & p-value & q-value & GO (Biological Process) \\
\hline 1 & P07954 & $\begin{array}{l}\text { Fumarate hydratase, } \\
\text { mitochondrial }\end{array}$ & 54714 & 8.85 & 408 & 27.2 & 8.27 & $2.10 \mathrm{E}-03$ & 4.68E-04 & $\begin{array}{c}\text { GO:0009056 catabolic process, GO:0042592 homeostatic } \\
\text { process }\end{array}$ \\
\hline 2 & Q16836 & $\begin{array}{l}\text { Hydroxyacyl-coenzyme A } \\
\text { dehydrogenase }\end{array}$ & 34613 & 8.76 & 118 & 21.5 & 4.81 & $3.22 \mathrm{E}-04$ & $1.38 \mathrm{E}-03$ & GO:0055114 oxidation reduction \\
\hline 3 & Q9Y281 & Cofilin-2 & 18764 & 7.66 & 113 & 33.1 & 7.4 & $2.75 \mathrm{E}-05$ & $1.75 \mathrm{E}-03$ & GO:0030042 actin filament depolymerization \\
\hline 4 & P60981 & Destrin & 18852 & 8.14 & 147 & 26.1 & 5.08 & $1.62 \mathrm{E}-04$ & $1.75 \mathrm{E}-03$ & $\begin{array}{c}\text { GO:0006928 cell motion, GO:0043243 positive regulation of } \\
\text { protein complex disassembly }\end{array}$ \\
\hline 5 & P23528 & Cofilin-1 & 18776 & 8.22 & 192 & 50.6 & 4.1 & $3.15 \mathrm{E}-03$ & $1.99 \mathrm{E}-03$ & $\begin{array}{c}\text { GO:0006928 cell motion, GO:0043243 positive regulation of } \\
\text { protein complex disassembly }\end{array}$ \\
\hline 6 & O00746 & $\begin{array}{l}\text { Nucleoside diphosphate } \\
\text { kinase }\end{array}$ & 17469 & 7.77 & 1024 & 41.4 & 2.7 & $3.71 \mathrm{E}-03$ & $2.34 \mathrm{E}-03$ & GO:0009116 nucleoside metabolic process \\
\hline 7 & Q9BYZ2 & $\begin{array}{l}\text { L-lactate dehydrogenase A- } \\
\text { like } 6 \mathrm{~B}\end{array}$ & 36817 & 7.62 & 244 & 29.6 & 4.52 & $1.02 \mathrm{E}-02$ & 4.48E-03 & GO:0055114 oxidation reduction, GO:0006096 glycolysis \\
\hline 8 & P04083 & Annexin A1 & 38816 & 6.57 & 142 & 6.62 & 1.88 & $3.49 \mathrm{E}-03$ & 4.48E-03 & $\begin{array}{c}\text { GO:00070301 cellular response to hydrogen peroxide, } \\
\text { GO:0006954 inflammatory response }\end{array}$ \\
\hline 9 & Q99497 & Protein DJ-1 & 20064 & 6.33 & 501 & 21.2 & 8.58 & 4.11E-04 & 4.48E-03 & $\begin{array}{c}\text { GO:0006979 response to oxidative stress, GO:0042592 } \\
\text { homeostatic process }\end{array}$ \\
\hline 10 & P30041 & Peroxiredoxin-6 & 25109 & 5.74 & 348 & 35.7 & 12.7 & 5.85E-04 & $5.26 \mathrm{E}-03$ & $\begin{array}{c}\text { GO:0009056 catabolic process, GO:0055114 oxidation } \\
\text { reduction }\end{array}$ \\
\hline 11 & P08670 & Vimentin & 53754 & 5.06 & 1536 & 62.2 & 0.08 & $2.21 \mathrm{E}-03$ & $5.26 \mathrm{E}-03$ & GO:0006928 cell motion \\
\hline 12 & P67936 & Tropomyosin alpha-4 chain & 28620 & 4.65 & 138 & 23.8 & 0.07 & $2.47 \mathrm{E}-02$ & $5.26 \mathrm{E}-03$ & GO:0006928 cell motion \\
\hline 13 & P09493 & Tropomyosin alpha-1 chain & 32746 & 4.69 & 405 & 33.1 & 0.12 & 2.37E-03 & $6.41 \mathrm{E}-03$ & $\begin{array}{c}\text { GO:0006979 response to oxidative stress, GO:0006928 cell } \\
\text { motion, GO:0046907 intracellular transport }\end{array}$ \\
\hline 14 & O14556 & $\begin{array}{l}\text { Glyceraldehyde-3- } \\
\text { phosphate dehydrogenase }\end{array}$ & 35953 & 8.49 & 1165 & 48.6 & 0.22 & $9.05 E-03$ & $1.04 \mathrm{E}-02$ & $\begin{array}{c}\text { GO:0055114 oxidation reduction, GO:0006096 } \sim \text { glycolysis, } \\
\text { GO:0006928 cell motion }\end{array}$ \\
\hline 15 & Q9UBR2 & Cathepsin Z & 34658 & 6.13 & 308 & 15.7 & 0.18 & 4.90E-03 & $1.04 \mathrm{E}-02$ & GO:0006508 proteolysis \\
\hline 16 & Q08752 & $\begin{array}{l}\text { Peptidyl-prolyl cis-trans } \\
\text { isomerase D }\end{array}$ & 20436 & 6.77 & 139 & 8.88 & 0.12 & $9.20 \mathrm{E}-03$ & $1.08 \mathrm{E}-02$ & $\begin{array}{l}\text { GO:0043065 positive regulation of } \\
\text { apoptotic process }\end{array}$ \\
\hline 17 & Q9Y4L1 & $\begin{array}{l}\text { Hypoxia up-regulated } \\
\text { protein } 1\end{array}$ & $1 E+05$ & 5.09 & 192 & 27 & N/A & N/A & N/A & $\begin{array}{l}\text { GO:0042221 response to chemical stimulus, } \\
\text { GO:0006950 response to stress }\end{array}$ \\
\hline 18 & P10809 & 60 kDa heat shock protein & 61105 & 5.72 & 289 & 29.6 & 4.77 & 8.26E-04 & 2.47E-02 & GO:0032943 mononuclear cell proliferation \\
\hline
\end{tabular}




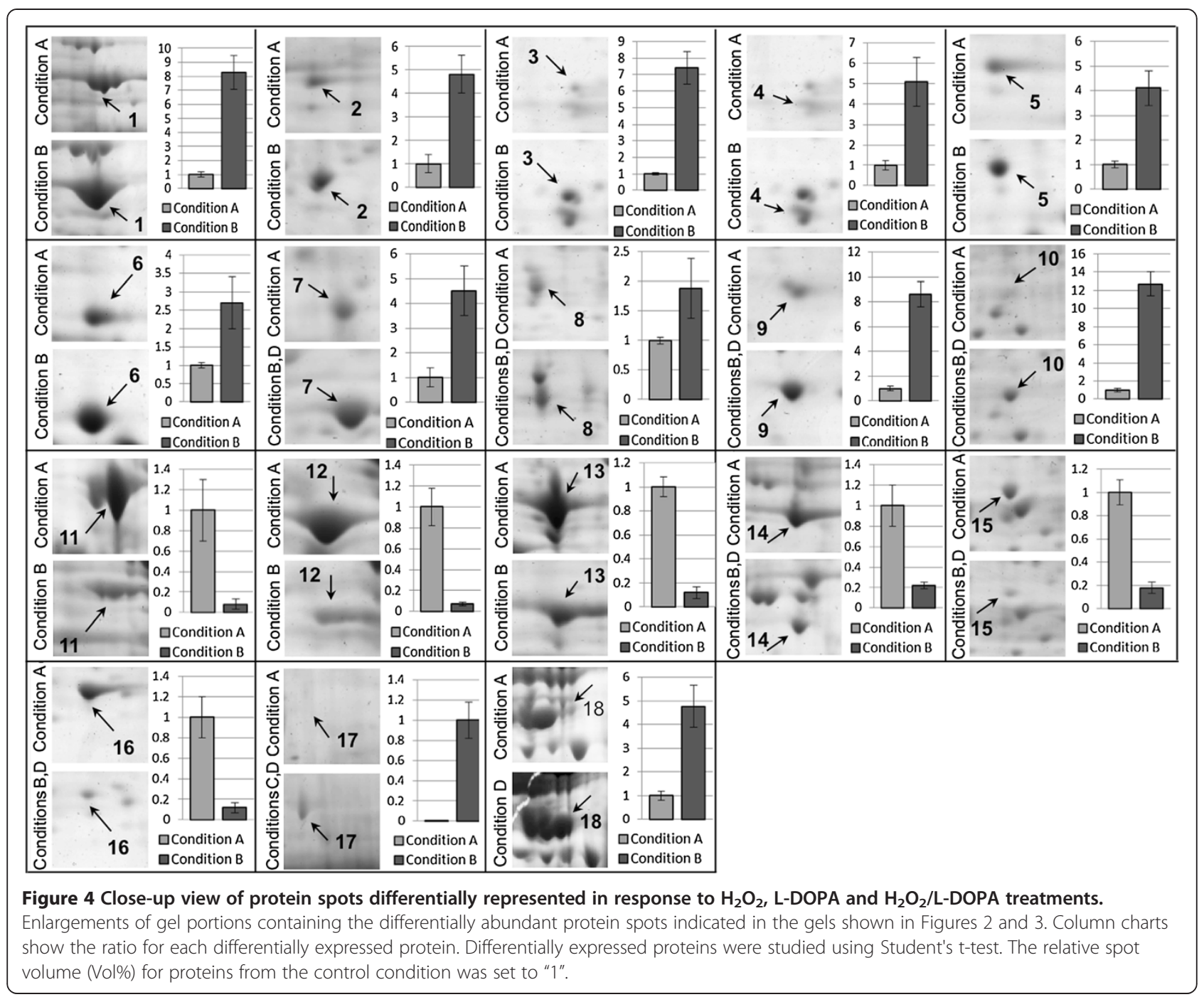

and mitochondrial regulation [30]. Similar to Annexin A1 and Peroxiredoxin-6, PARK7/DJ-1 is also a stress sensor and its expression is increased upon oxidative stress and various other stresses [31,32] playing a role in regulating the expression or stability of the mitochondrial uncoupling proteins SLC25A14 and SLC25A27 in dopaminergic neurons [33]. PARK7/DJ-1 is also a transcriptional coactivator that protects against neuronal apoptosis and it has been shown that its cytoprotective action is through inhibition of the p53-Bax-caspase pathway [34]. Moreover, it is known that PARK7/DJ-1 also enhances cell survival through the binding of Cezanne, a negative regulator of NF-kappaB [35].

It is also interesting to note that Cathepsin $\mathrm{X}$ (also known as Cathepsin Z, spot 15, ratio 0.18), involved in cell death, is attenuated (Table 2). This protein is a lysosomal cysteine proteinase and a member of the peptidase $\mathrm{C} 1$ family with both carboxy-monopeptidase and carboxydipeptidase activities [36]. It has been reported that $\alpha$ and $\gamma$ enolases, showing neurotrophic activity, are molecular targets for Cathepsin $\mathrm{X}$ and that cleavage of C-terminal amino acids of $\alpha$ and $\gamma$ enolases by Cathepsin $\mathrm{X}$ abolishes their neurotrophic activity affecting neuronal cell survival and neuritogenesis [37].

Down-regulation of Cyclophilin D (spot 16, ratio 0.12), the only human mitochondrial isoform of cyclophilins, is also notable (Table 2). Cyclophilin D is required for the formation of the mitochondrial permeability transition pore leading to cell necrosis [38]. In addition, opening of the mitochondrial permeability transition pore, orchestrated by Cyclophilin D, underlies oxidative stress-induced axonal degeneration [39]. Therefore attenuation of this protein in response to oxidative stress seems to play a pivotal role in cell survival.

\section{Cytoskeletal modifications by oxidative stress}

Treatment with $\mathrm{H}_{2} \mathrm{O}_{2}$ resulted in modification of cell morphology in the absence of L-DOPA (Figure 1A). Indeed, 
the alteration of several structural proteins, in response to oxidative stress, indicates a rearrangement of the cytoskeleton. We observed up-regulation of all three members of the ADF/cofilin family including Cofilin-1 (spot 5, 4.1 fold), Cofilin-2 (spot 3, 7.4 fold) and Destrin, also known as ADF or actin depolymerizing factor (spot 4, 5.08 fold) (Table 2). Cofilins control actin polymerization/depolymerization in a $\mathrm{pH}$-sensitive manner where they bind to actin filaments (F actin) and regulate actin cytoskeleton dynamics playing a critical role in the regulation of cytoskeletal organization and cell morphology [40].

Conversely, other actin binding proteins, such as Tropomyosin alpha-4 chain (spot 12, ratio 0.07 ) and Tropomyosin alpha-1 chain (spot 13, ratio 0.12 ) are down-regulated (Table 2). These proteins bind to actin filaments in muscle and non-muscle cells and play a central role in muscle contraction and in stabilizing cytoskeleton actin filaments in non-muscle cells [41].

The down-regulation of Vimentin (spot 11, ratio 0.08 ) under oxidative conditions is also remarkable (Table 2). Vimentin is attached to the endoplasmic reticulum, mitochondria and nucleus either laterally or terminally [42]. This cytoskeletal component plays an important role in anchoring organelles in the cytosol and is responsible for maintaining cell shape, cytoplasmic integrity, and stabilization of cytoskeletal interactions [43]. Cells deficient in Vimentin are therefore extremely delicate [43] suggesting that the observed change in neuronal cell morphology in response to $\mathrm{H}_{2} \mathrm{O}_{2}$ may be due to the observed attenuation of Vimentin (Table 2).

\section{L-DOPA promotes reversal of oxidative stress responses}

An interesting phenomenon that was observed in our treatments is the ability of L-DOPA to reverse the effects of $\mathrm{H}_{2} \mathrm{O}_{2}$ on cellular morphology and cell viability (Figure 1 ). This reversal was also observed in terms of ROS where LDOPA exposure reduced ROS levels, in the presence of $\mathrm{H}_{2} \mathrm{O}_{2}$, down to levels observed in control cells (Figure 5). Indeed, all the $\mathrm{H}_{2} \mathrm{O}_{2}$-induced protein alterations, affecting the cytoskeleton, were restored to baseline by supplementing the $\mathrm{H}_{2} \mathrm{O}_{2}$-containing media with L-DOPA (spots 3, 4, 5, 11, 12 and 13) (Figures 3B, Table 2). Furthermore, the induction of mitochondrial enzymes under oxidative stress condition (fumarate hydratase (spot 1), nucleosidediphosphate kinase (spot 6) and 3-Hydroxyacyl CoA dehydrogenase (spot 2) was abolished in response to L-DOPA exposure (Table 2).

\section{Effects of L-DOPA}

Only cells exposed to L-DOPA under oxidative stress conditions show significantly elevated expression of a $60-\mathrm{kDa}$ heat shock protein (also known as HSP-60, spot 18, 4.77 fold overexpressed), a mitochondrial protein with cytoprotective functions [44]. This observation suggests that L-

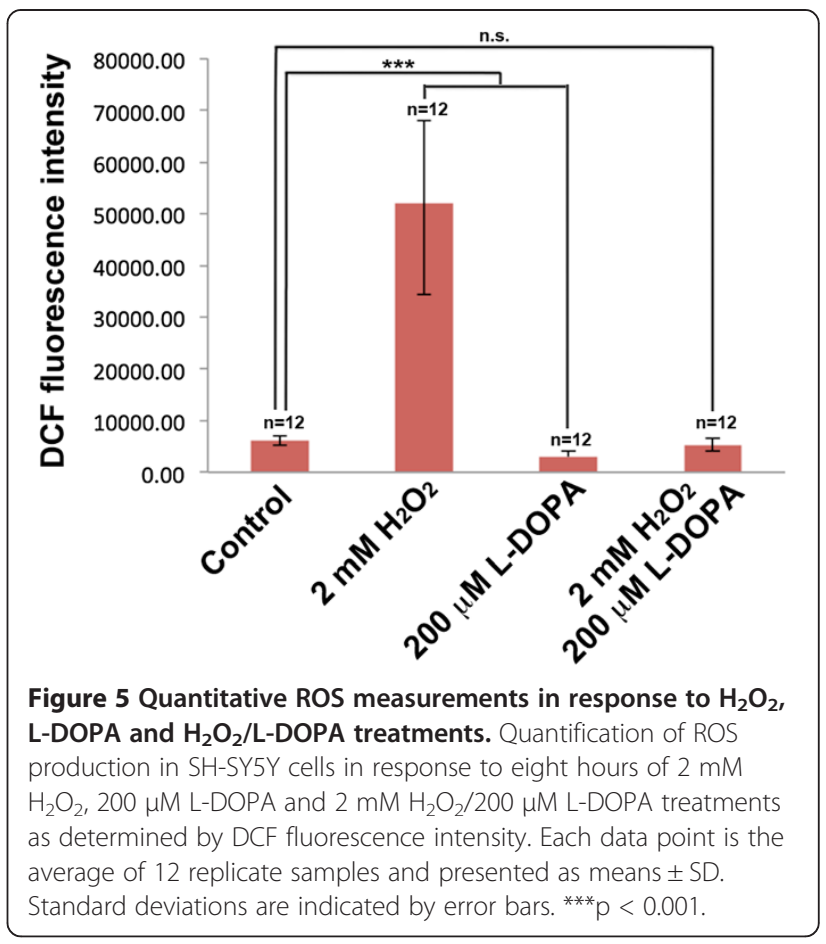

DOPA can mediate mitochondrial associated cell survival mechanisms as has been previously reported when exposing postnatal mesencephalic cultures, grown on glia monolayers, to L-DOPA in excess of $100 \mu \mathrm{M}$ [45]. This heat shock protein contributes to the anti-apoptotic Hsp60/procaspase-3 complex and enhances cell survival [46]. It has been observed that mild Hsp60 deficiency primarily affects neuronal and/or glia cells, whereas more severe Hsp60 deficiency affects all tissues [47].

In addition to its effects on the cytoskeleton and mitochondria, L-DOPA seems to participate in a cell survival mechanism triggered by oxygen deprivation through induction of the hypoxia up-regulated protein 1 (ORP150, spot 17), a chaperone involved in protein folding [48]. We observed detectable levels of this protein only in the presence of L-DOPA regardless of the oxidative stress conditions (Table 2) suggesting that L-DOPA may aid hypoxia condition in cells. It has been shown in rat astrocytes that ORP150 is induced by hypoxia within 24 hours, augmented further during early re-oxygenation, and thereafter decreasing to baseline levels by 24 hours in normoxia [49]. Furthermore, the hypoxia-mediated induction of ORP150 appears specific as stress conditions such as heat shock, $\mathrm{H}_{2} \mathrm{O}_{2}$, cobalt chloride, 2-deoxyglucose, or tunicamycin does not affect ORP150 levels [49]. Interestingly, exposure to dopamine has similar ORP induction effects as hypoxia in PC12 cells [50]. In the catecholamine synthesis pathway dopamine is the first catecholamine synthesized from LDOPA where norepinephrine and epinephrine are formed by further metabolic dopamine modifications (Figure 6). 


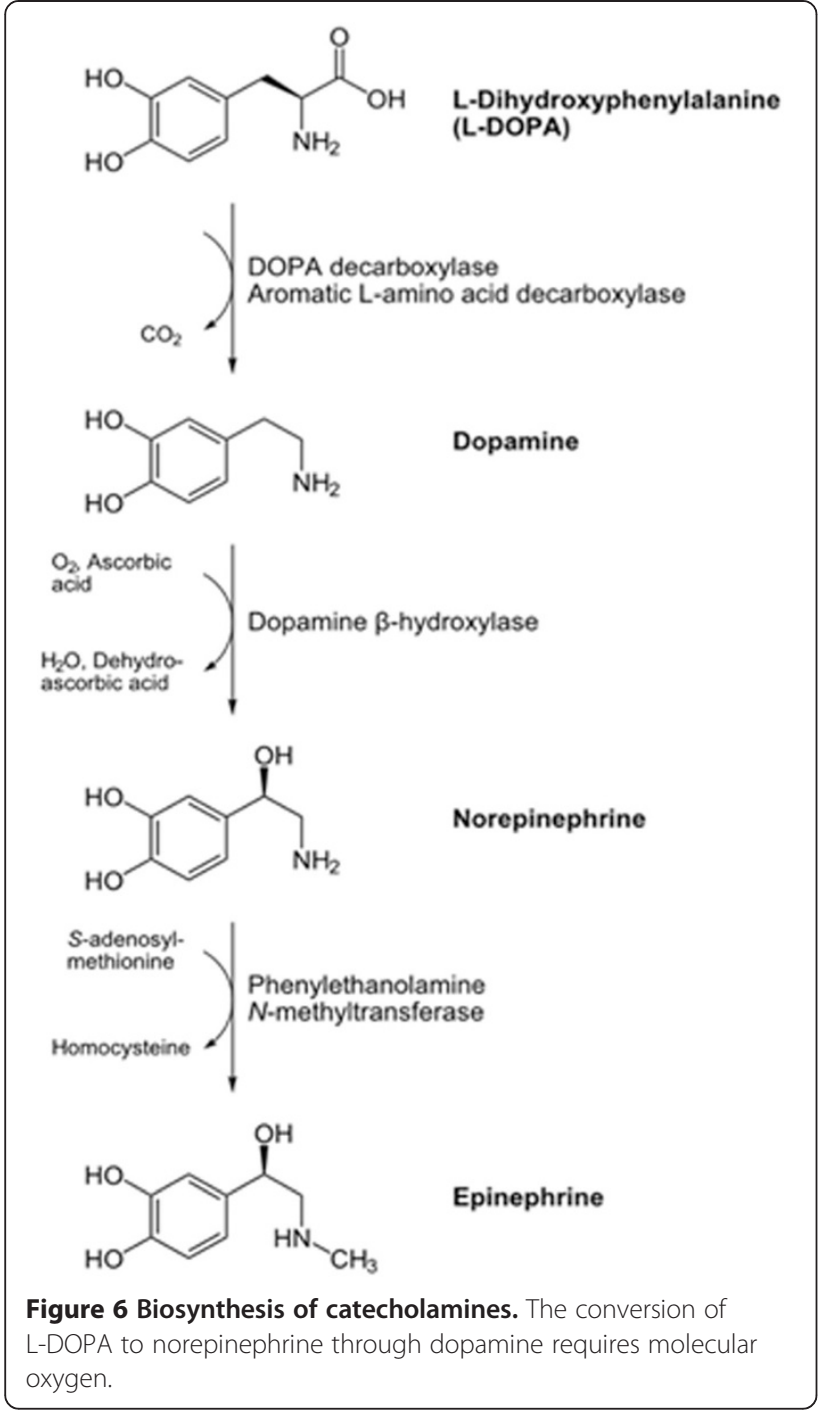

The conversion of dopamine to norepinephrine requires oxygen, thus the higher level of oxygen consumption due to L-DOPA exposure may cause cellular hypoxia and therefore induction of ORP150 with its concomitant cytoprotective effects.

Our findings, combined with previous data, suggest that although L-DOPA appears to influence neuronal cell survival pathways, this is most probably an indirect effect through the induction of endogenous antioxidant mechanisms [15].

\section{Conclusion}

There is clear controversy surrounding L-DOPA effects associated with oxidative stress [16]. Using a 2DE-based proteomic study we have shown that oxidative stress changes neuronal metabolic routes and affects cytoskeletal integrity. Interestingly, L-DOPA reverses some of these $\mathrm{H}_{2} \mathrm{O}_{2-}$ mediated effects at the cell morphology and cell viability level (Figure 1), at the ROS level (Figure 5) and at the protein level (Table 2). Exposure to L-DOPA may aid hypoxia condition in cells and therefore induction of ORP150 with its concomitant cytoprotective effects. However, L-DOPA exposure may simply evoke endogenous antioxidant mechanisms [15] and it cannot be ruled out that L-DOPA has direct ROS scavenging action [16]. Our study sheds light on the molecular interplay linking oxidative stress and L-DOPA in neuronal cells. Furthermore, the data presented here highlights the complex nature of L-DOPA in PD, demonstrating that additional studies are required that addresses L-DOPA action in the context of appropriate experimental design and choice of model mimicking PD.

\section{Methods}

\section{Reagents and cell culture}

Fetal bovine serum (FBS), phosphate buffered saline (PBS), Dulbecco's minimum essential medium plus F12 (DMEM/F12), penicillin and streptomycin were purchased from Invitrogen (Gaithersburg, MD). Acrylamide/ bis-acrylamide, tris base, glycine, ammonium persulfate, PVDF membrane, TEMED, DTT, SDS, urea, thiourea, glycerol, ammonium bicarbonate, DMSO, ECL reagent, bromoplenol blue were purchased from Fisher Scientific (Pittsburgh, PA). Trypsin and trypan blue were obtained from Sigma-Aldrich (St. Louis, MO).

SH-SY5Y cells were cultured in DMEM/F12 containing $10 \% \mathrm{FBS}, 100 \mathrm{U} / \mathrm{ml}$ penicillin and $100 \mathrm{mg} / \mathrm{ml}$ streptomycin at $37^{\circ} \mathrm{C}$ in an atmosphere containing $5 \%$ $\mathrm{CO}_{2}$. In order to perform treatments the media were supplemented with $2 \mathrm{mM} \mathrm{H}_{2} \mathrm{O}_{2}$ (Sigma-Aldrich, MO), $200 \mu \mathrm{M}$ L-DOPA (Acros Organics, NJ), or a combination of $\mathrm{H}_{2} \mathrm{O}_{2}$ /L-DOPA for eight hours (Table 1).

\section{Cell viability}

Cell viability was evaluated by the neutral red uptake assay. $5 \times 10^{4} \mathrm{SH}$-SY5Y cells/well were seeded in 96-well tissue culture plates and incubated overnight. The next day, the culture medium was removed and the cells were treated with either $2 \mathrm{mM} \mathrm{H}_{2} \mathrm{O}_{2}, 200 \mu \mathrm{M} \mathrm{L}$-DOPA and co-treated with $2 \mathrm{mM} \mathrm{H}_{2} \mathrm{O}_{2}$ and $200 \mu \mathrm{M}$ L-DOPA in serum-free medium for eight hours. Untreated cells were used as control. Following incubation, cell morphology was recorded using an EVOS phase-contrast inverted microscope. The test-medium was then removed and cells were washed with PBS. Then $100 \mu \mathrm{l}$ of a neutral red solution $(40 \mu \mathrm{g} / \mathrm{ml})$ was added in each well. The plates were incubated at $37^{\circ} \mathrm{C}$ for 2 hours. After incubation, the neutral red solution was removed and cells were washed with $150 \mu \mathrm{l}$ PBS per well. Following this $150 \mu \mathrm{l}$ neutral red destaining solution (50\% ethanol, 49\% deionized water, $1 \%$ glacial acetic acid) was added to the cells and the plates were rapidly shaken for at least 10 minutes. The absorbance was measured at $540 \mathrm{~nm}$ 
using an Epoch microplate spectrophotometer (BioTeck, VT). The results were reported as a percentage compared to control cells (considered as $100 \%$ viable).

\section{Detection of ROS formation}

Intracellular ROS levels were detected by measuring the oxidation of the cell-permeable dye 2', 7'-dichlorofluorescent diacetate (DCF-DA; Sigma-Aldrich, MO) to fluorescent DCF. To quantify intracellular ROS levels, $5 \times 10^{4}$ SH-SY5Y cells/well were seeded in black 96-well plates. The next day, the culture medium was removed and the cells were incubated for 45 minutes with $200 \mu \mathrm{l}$ of DCFDA (final concentration $25 \mu \mathrm{mol}$ )/well. After incubation cells were washed with $\mathrm{PBS}$ and exposed to $2 \mathrm{mM}$ $\mathrm{H}_{2} \mathrm{O}_{2}, 200 \mu \mathrm{M}$ L-DOPA and $2 \mathrm{mM} \mathrm{H} \mathrm{H}_{2} \mathrm{O}_{2} / 200 \mu \mathrm{M} \mathrm{L}-$ DOPA in serum-free medium for eight hours as described above. The medium was then removed and cells were washed again with PBS. Relative fluorescence was measured using a GloMax-Multi Detection System fluorescence plate reader (Promega, WI) at $485 \mathrm{~nm}$ excitation and $528 \mathrm{~nm}$ emission wavelengths.

\section{Protein sample preparation and 2-D gel electrophoresis}

Triplicate batches of SH-SY5Y cells were seeded at 20-30\% confluence and harvested when cell density reached $90 \%$. After three washes with PBS, healthy cells were harvested from the plates and solubilized in $500 \mu \mathrm{l}$ of lysis buffer: $8 \mathrm{M}$ urea, 4\% (w/v) 3-[(3-cholamidopropyl)dimethylammonio]1-propanesulfonate (CHAPS), 0.5\% (v/v) ampholytes (IPG buffer, GE Healthcare), $25 \mathrm{mM}$ DTT and 0.002\% bromophenol blue) and stored at $-80^{\circ} \mathrm{C}$. The insoluble fraction was discarded after centrifugation at 13,200 rpm for $5 \mathrm{~min}$. The supernatant was collected and the protein concentration was determined according to the Bradford method, which showed a high reproducibility for this protein extraction protocol.

A solution containing $850 \mu \mathrm{g}$ of soluble proteins in the sample buffer (same as lysis buffer but containing $2 \%$ CHAPS), was loaded onto 24-cm IPG strips (GE Healthcare), with non-linear (NL) pH 3-11 gradients. Focusing of proteins (using BioRad IEF instrument), equilibration of the focused IPG strips and the 12.5\% SDS-PAGE for the second dimension (carried out in an Ettan Dalt Six apparatus (GE Healthcare)) were performed as previously described [51]. Briefly, proteins were focused at $20^{\circ} \mathrm{C}$ according to the following program: $1 \mathrm{~h}, 0 \mathrm{~V}$ and $12 \mathrm{~h}, 30 \mathrm{~V}$ (rehydration); 30-min gradient to $10,000 \mathrm{~V}$; up to $9 \mathrm{~h}, 10,000 \mathrm{~V}$ until $85 \mathrm{kV}$-h. Focused IPG strips were equilibrated twice for $15 \mathrm{~min}$ in a buffer containing $50 \mathrm{mM}$ Tris- $\mathrm{HCl}$ (pH 8.8), $6 \mathrm{M}$ urea, 30\% (v/v) glycerol, $2 \%(\mathrm{w} / \mathrm{v})$ SDS, $0.002 \%$ bromphenol blue, and 1\% (w/v) DTT. For the second equilibration step, DTT was replaced by $4.0 \%(\mathrm{w} / \mathrm{v})$ iodoacetamide. In the second dimension $12.5 \%$ polyacrylamide SDS-PAGE gels were run in an Ettan Dalt Six apparatus (GE Healthcare) for $45 \mathrm{~min}$ at 3 watts/gel and then for $4 \mathrm{~h}$ at 18 watts/gel. Gels were stained with Colloidal Coomassie (CC) following the "blue silver" staining method (28), using $0.12 \%$ Coomassie Blue G-250 (Sigma), 10\% ammonium sulfate, $10 \%$ phosphoric acid, and $20 \%$ methanol $[52,53]$.

\section{Analysis of differential protein abundance}

Two-dimensional images were captured by scanning stained gels using an ImageScanner II (GE Healthcare) previously calibrated by using a grayscale marker (Eastman Kodak Co.), digitalized with Labscan 5.00 (v1.0.8) software (GE Healthcare), and analyzed with the ImageMasterTM 2D Platinum V7.0 software (GE Healthcare). Three gels for each condition, obtained from three independent cultures (biological replicates), were analysed to guarantee representative results. After automated spot detection, spots were checked manually to eliminate any possible artefacts, such as streaks or background noise. The patterns of each sample were overlapped and matched, using landmark features, to detect differentially expressed proteins. Variability in the number of protein spots detected among biological replicates was less than $10 \%$, which may be due to experimental variability. Spot normalization (internal calibration to make the data independent from experimental variations between gels) was made using relative volumes to quantify the gel spots. Relative spot volume (Vol\%) corresponds to the volume of each spot divided by the total volume of all the spots in the gel. Analysis of each differentially expressed protein between conditions was performed using Student's t-test and $\mathrm{p}<0.05$ was considered statistically significant $[51,54,55]$. False discovery rate (FDR) correction for multiple hypothesis testing was performed according to Storey's method (q-value <0.05) [56]. Differentially expressed proteins were studied further when the ratio of the relative mean volume for one specific spot (in three biological replicates) was higher than 1.5 fold (the relative spot volume (Vol\%) for proteins from the control condition was set to "1").

\section{Protein identification by mass spectrometry}

The protein spots of interest were manually excised from the gel and washed three times with ammonium bicarbonate/acetonitrile 1:1 (vol/vol) solution. Polyacrylamide fragments were dehydrated in acetonitrile and dried with a vacuum concentrator. Protein reduction and alkylation were performed by reswelling polyacrylamide fragments in $25 \mathrm{mM}$ ammonium carbonate solution containing $0.15 \mathrm{mg} / \mathrm{ml} \mathrm{DTT}$ at $56^{\circ} \mathrm{C}$. This solution was replaced by a $25 \mathrm{mM}$ ammonium bicarbonate solution containing $10 \mathrm{mg} / \mathrm{ml}$ 2-iodoacetamide (Bio-Rad) for $45 \mathrm{~min}$ at room temperature and in the dark. Fragments were dried as described above and tryptic cleavage was 
initiated by reswelling the gel in $25 \mathrm{mM}$ ammonium bicarbonate solution containing $0.1 \mu \mathrm{g}$ trypsin per gel slice (Promega, WI, USA) for 20 min on ice. The solution was then replaced by $25 \mathrm{mM}$ ammonium carbonate solution and digestion carried out overnight at $37^{\circ} \mathrm{C}$. Tryptic peptides were extracted at $37^{\circ} \mathrm{C}$ for $15 \mathrm{~min}$ with a $50 \%$ (vol/ vol) acetonitrile and 10\% (vol/vol) acetic acid solution. A second extraction was performed under the same conditions. A third extraction was performed at room temperature for 15 min with $100 \%$ acetonitrile. The pooled solution was dried under vacuum and resuspended in $10 \mu \mathrm{l} 0.1 \%$ (vol/vol) formic acid solution.

Five microliters of each sample were loaded onto a $75 \mu \mathrm{m} \times 12 \mathrm{~cm}$ column self-packed with $3 \mu \mathrm{m}$ ReproSilPur C18-AQ beads (Dr. Maisch), eluted with a gradient of $0-40 \%$ acetonitrile in $0.1 \%$ formic acid over $18 \mathrm{~min}$ at $300 \mathrm{nl} / \mathrm{min}$ using an Exigent nanoflow HPLC coupled directly to an LTQ-Orbitrap mass spectrometer (Thermo Fisher Scientific). Mass spectra were acquired in data-dependent analysis mode with one 60000 resolution MS survey scan by the Orbitrap and up to eight concurrent MS/MS scans in the LTQ for the eight most intense peaks selected from each survey scan. Automatic gain control was set to 2000 000 for Orbitrap survey scans and 5000 for LTQ MS/MS scans. Survey scans were acquired in profile mode and MS/MS scans were acquired in centroid mode. Mascot generic format files were generated from the raw data using DTASuperCharge (version 1.01) for database searching. Mascot Generic Files combining MS and MS/ MS spectra were automatically created for protein identification, and used to interrogate a nonredundant protein database using a local license of Mascot v 2.2 from Matrix Science through the Protein Global Server (GPS) v 3.6 (Applied Biosystems). The search parameters were set as follows: (i) NCBInr (2011.11.21) sequence database was used; (ii) taxonomy: All entries (16245521 sequences; 5585386883 residues); (iii) fixed and variable modifications were considered (Cys as S carbamidomethyl derivative and Met as oxidized methionine); (iv) one missed cleavage site was allowed; (v) precursor tolerance was $100 \mathrm{ppm}$ and MS/MS fragment tolerance was $0.3 \mathrm{Da}$; (vi) peptide charge: $1+$; and (vii) the algorithm was set to use trypsin as the enzyme. Additional criteria for confident identification were that the protein match should have at least $15 \%$ sequence coverage; for a lower coverage, only those proteins with a Mascot ions score above 54 and at least two peptides identified in the tandem MS analysis (with a significance level of $\mathrm{p}<0.05$ ), were considered valid.

\section{Competing interests}

The authors declare that they have no competing interests.

\section{Authors' contributions}

MSJ, RP, and SGM designed the research; MSJ carried out the cell culture, treatment optimization, 2-DE and gel analysis. RP performed the cell viability and ROS measurements. MSJ and EH carried out the protein identification.
MSJ carried out the data analysis and interpretation of proteomic results. SGM, TAN, and JPL led the research; MSJ, RP, and SGM wrote the paper. All of the authors have been involved in revising the manuscript and have given final approval of the version to be published.

\section{Acknowledgements}

This work was supported by the Norwegian Research Council (SGM), The Western Norway Regional Health Authority (SGM), The Norwegian Centre for Movement Disorders (JPL), NIH NINDS grant P30 NS050276 (TAN) and 100 Women in Hedge Funds Grant (TAN). We thank Steven Blais for advice on mass spectrometry.

\section{Author details}

'Department of Biological Sciences, St John's University, New York, NY, USA ${ }^{2}$ Kimmel Center for Biology and Medicine at the Skirball Institute and Department of Biochemistry and Molecular Pharmacology, New York University School of Medicine, New York, NY, USA. ${ }^{3}$ The Norwegian Centre for Movement Disorders, Stavanger University Hospital, Stavanger, Norway. ${ }^{4}$ Cellular and Molecular Research Center, School of Medicine, Shahrekord University of Medical Sciences, Shahrekord, Iran.

Received: 14 January 2014 Accepted: 23 July 2014

Published: 31 July 2014

\section{References}

1. De Lau LML, Breteler MMB: Epidemiology of Parkinson's disease. Lancet Neurol 2006, 5:525-535.

2. Dorsey ER, Constantinescu R, Thompson JP, Biglan KM, Holloway RG, Kieburtz K, Marshall FJ, Ravina BM, Schifitto G, Siderowf A, Tanner CM: Projected number of people with Parkinson disease in the most populous nations, 2005 through 2030. Neurology 2007, 68:384-386.

3. Davie CA: A review of Parkinson's disease. Br Med Bull 2008, 86:109-127.

4. Dawson TM, Ko HS, Dawson VL: Genetic animal models of Parkinson's disease. Neuron 2010, 66:646-661.

5. Bosco DA, Fowler DM, Zhang Q, Nieva J, Powers ET, Wentworth P, Lerner RA, Kelly JW: Elevated levels of oxidized cholesterol metabolites in Lewy body disease brains accelerate alpha-synuclein fibrilization. Nat Chem Biol 2006, 2:249-253.

6. Nakabeppu Y, Tsuchimoto D, Yamaguchi H, Sakumi K: Oxidative damage in nucleic acids and Parkinson's disease. J Neurosci Res 2007, 85:919-934.

7. Zeevalk GD, Razmpour R, Bernard LP: Glutathione and Parkinson's disease: is this the elephant in the room? Biomed Pharmacother 2008, 62:236-249.

8. Mena MA, Casarejos MJ, Solano RM, de Yébenes JG: Half a century of LDOPA. Curr Top Med Chem 2009, 9:880-893.

9. Blessing $\mathrm{H}$, Bareiss M, Zettlmeisl H, Schwarz J, Storch A: Catechol-Omethyltransferase inhibition protects against 3,4-dihydroxyphenylalanine (DOPA) toxicity in primary mesencephalic cultures: new insights into levodopa toxicity. Neurochem Int 2003, 42:139-151.

10. Reksidler AB, Lima MMS, Dombrowski PA, Barnabé GF, Andersen ML, Tufik S, Vital MABF: Distinct effects of intranigral L-DOPA infusion in the MPTP rat model of Parkinson's disease. J Neural Transm Supp/ 2009, 73:259-268.

11. Gołembiowska K, Dziubina A, Kowalska M, Kamińska K: Paradoxical effects of adenosine receptor ligands on hydroxyl radical generation by L-DOPA in the rat striatum. Pharmacol Rep 2008, 60:319-330.

12. Itokawa K, Ohkuma A, Araki N, Tamura N, Shimazu K: Effect of L-DOPA on nitric oxide production in striatum of freely mobile mice. Neurosci Lett 2006, 402:142-144

13. Li CL, Werner P, Cohen G: Lipid peroxidation in brain: interactions of LDOPA/dopamine with ascorbate and iron. Neurodegeneration 1995 4:147-153.

14. Spencer JP, Jenner A, Butler J, Aruoma OI, Dexter DT, Jenner P, Halliwell B: Evaluation of the pro-oxidant and antioxidant actions of L-DOPA and dopamine in vitro: implications for Parkinson's disease. Free Radic Res 1996, 24:95-105.

15. Han SK, Mytilineou C, Cohen G: L-DOPA up-regulates glutathione and protects mesencephalic cultures against oxidative stress. J Neurochem 1996, 66:501-510.

16. Lipski J, Nistico R, Berretta N, Guatteo E, Bernardi G, Mercuri NB: L-DOPA: a scapegoat for accelerated neurodegeneration in Parkinson's disease? Prog Neurobiol 2011, 94:389-407. 
17. Pompella A, Visvikis A, Paolicchi A, De Tata V, Casini AF: The changing faces of glutathione, a cellular protagonist. Biochem Pharmacol 2003, 66:1499-1503

18. Agarwal AR, Zhao L, Sancheti H, Sundar IK, Rahman I, Cadenas E: Shortterm cigarette smoke exposure induces reversible changes in energy metabolism and cellular redox status independent of inflammatory responses in mouse lungs. Am J Physiol Lung Cell Mol Physiol 2012, 303:L889-L898.

19. Ralser M, Wamelink MM, Kowald A, Gerisch B, Heeren G, Struys EA, Klipp E, Jakobs C, Breitenbach M, Lehrach $H$, Krobitsch S: Dynamic rerouting of the carbohydrate flux is key to counteracting oxidative stress. J Biol 2007 $6: 10$.

20. Hara MR, Thomas B, Cascio MB, Bae B-I, Hester LD, Dawson VL, Dawson TM, Sawa A, Snyder SH: Neuroprotection by pharmacologic blockade of the GAPDH death cascade. Proc Natl Acad Sci U S A 2006, 103:3887-3889.

21. Markert CL: Lactate dehydrogenase. Biochemistry and function of lactate dehydrogenase. Cell Biochem Funct 1984, 2:131-134.

22. McNeil AK, Rescher U, Gerke V, McNeil PL: Requirement for annexin A1 in plasma membrane repair. J Biol Chem 2006, 281:35202-35207.

23. Varticovski L, Chahwala SB, Whitman M, Cantley L, Schindler D, Chow EP, Sinclair LK, Pepinsky RB: Location of sites in human lipocortin I that are phosphorylated by protein tyrosine kinases and protein kinases $A$ and $C$. Biochemistry 1988, 27:3682-3690.

24. Zhang Z, Huang L, Zhao W, Rigas B: Annexin 1 induced by antiinflammatory drugs binds to NF-kappaB and inhibits its activation: anticancer effects in vitro and in vivo. Cancer Res 2010, 70:2379-2388.

25. Gorecka KM, Konopka-Postupolska D, Hennig J, Buchet R, Pikula S: Peroxidase activity of annexin 1 from Arabidopsis thaliana. Biochem Biophys Res Commun 2005, 336:868-875.

26. Rhee HJ, Kim GY, Huh JW, Kim SW, Na DS: Annexin I is a stress protein induced by heat, oxidative stress and a sulfhydryl-reactive agent. Eur J Biochem 2000, 267:3220-3225.

27. Rhee SG, Chae HZ, Kim K: Peroxiredoxins: a historical overview and speculative preview of novel mechanisms and emerging concepts in cell signaling. Free Radic Biol Med 2005, 38:1543-1552.

28. Fisher $A B$ : Peroxiredoxin 6: a bifunctional enzyme with glutathione peroxidase and phospholipase $\mathrm{A}_{2}$ activities. Antioxid Redox Signal 2011, 15:831-844.

29. Tulsawani R, Kelly LS, Fatma N, Chhunchha B, Kubo E, Kumar A, Singh DP: Neuroprotective effect of peroxiredoxin 6 against hypoxia-induced retinal ganglion cell damage. BMC Neurosci 2010, 11:125

30. Ariga H, Takahashi-Niki K, Kato I, Maita H, Niki T, Iguchi-Ariga SMM: Neuroprotective function of DJ-1 in Parkinson's disease. Oxid Med Cell Longev 2013, 2013:683920.

31. Shendelman S, Jonason A, Martinat C, Leete T, Abeliovich A: DJ-1 is a redox-dependent molecular chaperone that inhibits alpha-synuclein aggregate formation. PLOS Biol 2004, 2:e362.

32. Yokota T, Sugawara K, Ito K, Takahashi R, Ariga H, Mizusawa H: Down regulation of DJ-1 enhances cell death by oxidative stress, ER stress, and proteasome inhibition. Biochem Biophys Res Commun 2003, 312:1342-1348.

33. Guzman JN, Sanchez-Padilla J, Wokosin D, Kondapalli J, llijic E, Schumacker PT, Surmeier DJ: Oxidant stress evoked by pacemaking in dopaminergic neurons is attenuated by DJ-1. Nature 2010, 468:696-700.

34. Fan J, Ren H, Jia N, Fei E, Zhou T, Jiang P, Wu M, Wang G: DJ-1 decreases Bax expression through repressing p53 transcriptional activity. J Biol Chem 2008, 283:4022-4030.

35. McNally RS, Davis BK, Clements CM, Accavitti-Loper MA, Mak TW, Ting JP-Y: DJ-1 enhances cell survival through the binding of Cezanne, a negative regulator of NF-kappaB. J Biol Chem 2011, 286:4098-4106.

36. Klemencic I, Carmona AK, Cezari MH, Juliano MA, Juliano L, Guncar G, Turk D, Krizaj I, Turk V, Turk B: Biochemical characterization of human cathepsin $\mathrm{X}$ revealed that the enzyme is an exopeptidase, acting as carboxymonopeptidase or carboxydipeptidase. Eur J Biochem 2000, 267:5404-5412.

37. Kos J, Jevnikar Z, Obermajer N: The role of cathepsin $\mathrm{X}$ in cell signaling. Cell Adhes Migr 2009, 3:164-166.

38. Linard D, Kandlbinder A, Degand H, Morsomme P, Dietz K-J, Knoops B: Redox characterization of human cyclophilin D: identification of a new mammalian mitochondrial redox sensor? Arch Biochem Biophys 2009, 491:39-45.
39. López-Erauskin J, Ferrer I, Galea E, Pujol A: Cyclophilin D as a potential target for antioxidants in neurodegeneration: the X-ALD case. Biol Chem 2013, 394:621-629.

40. Bravo-Cordero JJ, Magalhaes MAO, Eddy RJ, Hodgson L, Condeelis J: Functions of cofilin in cell locomotion and invasion. Nat Rev Mol Cell Biol 2013, 14:405-415.

41. Lin JJ-C, Eppinga RD, Warren KS, McCrae KR: Human tropomyosin isoforms in the regulation of cytoskeleton functions. Adv Exp Med Biol 2008, 644:201-222.

42. Katsumoto T, Mitsushima A, Kurimura T: The role of the vimentin intermediate filaments in rat 3Y1 cells elucidated by immunoelectron microscopy and computer-graphic reconstruction. Biol Cell 1990, 68:139-146.

43. Goldman RD, Khuon S, Chou YH, Opal P, Steinert PM: The function of intermediate filaments in cell shape and cytoskeletal integrity. J Cell Biol 1996, 134:971-983

44. Takada M, Otaka M, Takahashi T, Izumi Y, Tamaki K, Shibuya T, Sakamoto N, Osada T, Yamamoto S, Ishida R, Odashima M, Itoh H, Watanabe S: Overexpression of a $60-\mathrm{kDa}$ heat shock protein enhances cytoprotective function of small intestinal epithelial cells. Life Sci 2010, 86:499-504.

45. Mena MA, Davila $V$, Sulzer D: Neurotrophic effects of L-DOPA in postnatal midbrain dopamine neuron/cortical astrocyte cocultures. J Neurochem 1997, 69:1398-1408.

46. Campanella C, Bucchieri F, Ardizzone NM, Marino Gammazza A, Montalbano A, Ribbene A, Di Felice V, Bellafiore M, David S, Rappa F, Marasà M, Peri G, Farina F, Czarnecka AM, Conway de Macario E, Macario AJL, Zummo G, Cappello F: Upon oxidative stress, the antiapoptotic Hsp60/procaspase-3 complex persists in mucoepidermoid carcinoma cells. Eur J Histochem 2008, 52:221-228

47. Bross $P$, Magnoni R, Bie AS: Molecular chaperone disorders: defective Hsp60 in neurodegeneration. Curr Top Med Chem 2012, 12:2491-2503.

48. Ozawa K: 150-kDa Oxygen-regulated Protein (ORP150) Suppresses Hypoxia-induced Apoptotic Cell Death. J Biol Chem 1999, 274:6397-6404.

49. Matsumoto M: Purification and Characterization of a Novel Stress Protein, the 150-kDa Oxygen-regulated Protein (ORP150), from Cultured Rat Astrocytes and Its Expression in Ischemic Mouse Brain. J Biol Chem 1996, 271:5025-5032.

50. Dukes AA, Van Laar VS, Cascio M, Hastings TG: Changes in endoplasmic reticulum stress proteins and aldolase $A$ in cells exposed to dopamine. J Neurochem 2008, 106:333-346.

51. Jami M-S, Barreiro C, García-Estrada C, Martín J-F: Proteome analysis of the penicillin producer Penicillium chrysogenum: characterization of protein changes during the industrial strain improvement. Mol Cell Proteomics 2010, 9:1182-1198.

52. Candiano G, Bruschi M, Musante L, Santucci L, Ghiggeri GM, Carnemolla B, Orecchia P, Zardi L, Righetti PG: Blue silver: a very sensitive colloidal Coomassie G-250 staining for proteome analysis. Electrophoresis 2004, 25:1327-1333.

53. Kosalková K, García-Estrada C, Barreiro C, Flórez MG, Jami MS, Paniagua MA Martín JF: Casein phosphopeptides drastically increase the secretion of extracellular proteins in Aspergillus awamori. Proteomics studies reveal changes in the secretory pathway. Microb Cell Factories 2012, 11:5.

54. García-Estrada C, Barreiro C, Jami M-S, Martín-González J, Martín J-F: The inducers 1,3-diaminopropane and spermidine cause the reprogramming of metabolism in Penicillium chrysogenum, leading to multiple vesicles and penicillin overproduction. J Proteome 2013, 85:129-159.

55. Jami M-S, García-Estrada C, Barreiro C, Cuadrado A-A, Salehi-Najafabadi Z, Martín J-F: The Penicillium chrysogenum extracellular proteome. Conversion from a food-rotting strain to a versatile cell factory for white biotechnology. Mol Cell Proteomics 2010, 9:2729-2744.

56. Storey JD: A direct approach to false discovery rates. $J R$ Stat Soc Series $B$ Stat Methodol 2002, 64:479-498.

doi:10.1186/1471-2202-15-93

Cite this article as: Jami et al:: Proteome analysis reveals roles of L-DOPA in response to oxidative stress in neurons. BMC Neuroscience 2014 15:93. 